\title{
Adherence to Lifestyle Advice and Treatments in Pakistani Patients with Type 2 Diabetes Mellitus
}

\author{
Sarwar Malik ${ }^{*}$, Rabia Basit ${ }^{2}$, Sabahat Naz ${ }^{3}$, Minaz Mawani', Muhammad Qamar Masood ${ }^{5}$, \\ Jaweed Akhter ${ }^{5}$ \\ ${ }^{1}$ MBBS, FCPS (Medicine), FCPS (Endocrinology), Fellowship in Diabetes, Metabolism and Endocrinology, \\ Department of Medicine, Federal Govt. Polyclinic Hospital, Islamabad, Pakistan \\ ${ }^{2}$ MBBS, FCPS (Medicine), Fellowship in Diabetes, Metabolism and Endocrinology, Section of Endocrinology, \\ Department of Medicine, Aga Khan University, Karachi, Pakistan \\ ${ }^{3} \mathrm{MSc}$ (Food \& Nutrition), Section of Endocrinology, Department of Medicine, Aga Khan University, \\ Karachi, Pakistan \\ ${ }^{4} \mathrm{MSc}$ (Epidemiology and Biostatistics), Department of Medicine, Aga Khan University, Karachi, Pakistan \\ ${ }^{5} \mathrm{MBBS}$, FACE, Diplomat American Board of Internal Medicine and Endocrinology, Section of Endocrinology, \\ Department of Medicine, Aga Khan University, Karachi, Pakistan \\ Email: *drsarwar.malik@gmail.com,drrabiakhaleel@hotmail.com, sabahat.naz@aku.edu, \\ minaz.mawani@aku.edu, qamar.masood@aku.edu, jaweed.akhter@aku.edu
}

Received 22 November 2015; accepted 1 February 2016; published 6 February 2016

Copyright (C) 2016 by authors and Scientific Research Publishing Inc.

This work is licensed under the Creative Commons Attribution International License (CC BY). http://creativecommons.org/licenses/by/4.0/

(c) (i) Open Access

\section{Abstract}

Background: Type 2 diabetes mellitus (T2DM) is a chronic disease that has become a major health care concern, especially in developing countries like Pakistan. Lifestyle modification and appropriate pharmacotherapy are shown to improve blood glucose levels, lipid abnormalities and blood pressure. It is not known how many patients adhere to advice and drugs prescribed. This study aimed to determine adherence to lifestyle and therapeutic advice. Methods: A cross sectional hospital based study was conducted among patients attending the diabetic clinic at the Aga Khan University Hospital, using a structured questionnaire. Adult patients with T2DM and with at least one year duration of diabetes were included in the study. Results: Participants were aged between 32 and 92 years old with a mean age of 55.7 years old (SD \pm 10.7$)$. Mean duration of diabetes was 10.7 years old (SD \pm 7.7$)$. Majority $(94 \%)$ of the patients were literate. Around half $(47.3 \%)$ of the patients have had achieved glycemic target (HbA1c < 7\%). Above target glycemic control was more common among patients with ischemic heart disease $(68.1 \%)$, neuropathy $(64.8 \%)$ and those on insulin (62.5\%). Self-reported non-adherence for blood sugar monitoring $(9.5 \%)$, physi-

${ }^{*}$ Corresponding author.

How to cite this paper: Malik, S., Basit, R., Naz, S., Mawani, M., Masood, M.Q. and Akhter, J. (2016) Adherence to Lifestyle Advice and Treatments in Pakistani Patients with Type 2 Diabetes Mellitus. Journal of Diabetes Mellitus, 6, 49-57.

http://dx.doi.org/10.4236/jdm.2016.61006 
cal activity (61.7\%), tobacco use $(43.4 \%)$ and foot care $(43.9 \%)$ were noted. About $25 \%$ of the participants were not fully adherent to dietary advice. None of the patients from our study reported non-ad- herence to medications. Good adherence to physical activity was found in males with college degree. The highest percentage of tobacco use $(33.3 \%)$ was reported among businessmen. Conclusion: We noted low adherence to advice for physical activity, tobacco use and SMBG, but a high adherence to prescribed medications and insulin. This was a selected group visiting a teaching hospital. This will need to be studied further in the community and efforts are required to motivate patients.

\section{Keywords}

Type 2 Diabetes Mellitus, Adherence, Lifestyle advice, Treatment

\section{Introduction}

The prevalence of type 2 diabetes mellitus (T2DM) has been rising, especially in developing countries, alongside increasing obesity and sedentary lifestyles. It is a growing healthcare concern with an increasing impact on individuals, populations, and public health [1]. The International Diabetes Federation's most recent estimates indicate 382 million people worldwide ( $8.3 \%$ of adults) have diabetes, and the number of people with the disease is set to rise around 592 million by 2035 [1] [2]. T2DM remains a leading cause of cardiovascular diseases, blindness, amputation and renal diseases in most high income countries. With increasing prevalence of T2DM in low and middle income countries, similar complications are also expected to rise, leading to significant human and economic costs. International Diabetes Federation (IDF) has estimated diabetes national prevalence for Pakistan for the year 2013 to be $6.76 \%$ [2] [3].

Type 2 diabetes mellitus (T2DM) is a chronic, progressive disease characterized by insulin resistance along with defect in insulin secretion leading to hyperglycemia [4] [5]. It is a complex interaction between genetic factors, behavioral and environmental factors [4]. There is an established link between type 2 diabetes and modifiable risk factors such as obesity, smoking and physical inactivity [4] [6] [7]. Exercise training, often in combination with other lifestyle strategies, has shown beneficial effects on preventing the onset of T2DM and improving glycemic control in those with pre-diabetes [4] [7]-[10].

Adherence to prescribed lifestyle changes have been shown to improve blood glucose levels and also reduce dyslipidemia and blood pressure which are key risk factors for the development of micro and macro-vascular complications of diabetes [11]. Adherence to treatment has been defined as "the extent to which a person's behavior - taking medication, following a diet, and/or executing lifestyle changes—corresponds with agreed recommendations from a health care provider [12] [13]. A recent study conducted in Bangladesh showed non-adherence rates for: blood glucose monitoring (37\%), diet (44.8\%), foot care (43.2\%), exercise (33.2\%) and smoking (37.2\%) [14]. A study from Jordan reported that $81.4 \%$ of patients did not follow diabetes meal plans as recommended by the dietitians, two thirds (67.9\%) of patients did not participate in physical exercise and only $38.1 \%$ of patients monitored their blood glucose levels at home yet, most of the patients (91.9\%) were adherent to medication advice [15]. No data on adherence to lifestyle advice and treatment among diabetic patients has been reported from Pakistan

The primary objective of this study was to determine adherence to lifestyle advice and treatment among type 2 diabetic patients presenting to a tertiary care hospital in Karachi Pakistan, with specific evaluation of adherence to medication, dietary advice, blood sugar monitoring, physical activity and foot care. The secondary objective was to explore the relationship between adherence and factors such as gender, education, length and control of diabetes, occupation and ethnic background.

\section{Materials and Methods}

This was a cross-sectional study which was conducted at the Diabetes Clinic, Aga Khan University Hospital (AKUH), following approval from AKU-Ethics Review Committee.

Patients $\geq 18$ yrs old, who were diagnosed with type 2 diabetes mellitus for more than 1 year and during Sep- 
tember 2014 to November 2014, were included in the study following informed consent.

Data was collected through patient interviews and reviewing hospital records. A structured questionnaire was developed which comprised of questions on demographic information, duration of diabetes and duration of follow-up, family history, co-morbidities, clinical parameters, and medications. They were also asked questions on self-care practices for diabetes management such as compliance to medications, dietary advice, physical activity, blood glucose monitoring foot care and refraining from any form of tobacco use.

Self-reported dietary compliance were categorized as good adherence (if participants mostly follow recommended dietary advice), partial adherence (if participant occasionally followed recommended dietary advice) and non-adherence (if patient did not follow any dietary advice)

Self-Reported good adherence to physical activity was consider if participants performed regular exercise/ walk > 150 minutes/week, Partial adherence, if participants performed 60 - 150 minutes of physical activity per/ week and non-adherence, if participants performed $<60$ minutes of physical activity per week.

Good, partial and non-adherence to blood sugar monitoring was considered if participants monitored blood sugar $>3$ times/week, 1 - 3 times/week and never respectively. Good, partial and not adherent to medication use (both for OHA and Insulin) were considered if self-reported compliance was $80 \%-100 \%, 50 \%-79 \%$ and $<50 \%$ respectively. Good adherence to foot care was considered if participants followed doctor's advice and examined their regularly. Good adherence to tobacco advice was considered if participants refrained from tobacco use after getting advice from the health care provider.

All analyses were conducted by using the Statistical package for social science SPSS version 19.0. Descriptive analyses were done for demographic and Laboratory features and presented as mean \pm standard deviation. Chi-squared tests were performed on categorical data to find the relationships between variables.

\section{Results}

\subsection{Participant's Characteristics}

During the study period a total of 264 patients (130 men and 134 women) were included in the study. Participants were aged between 32 and 92 years with a mean age of 55.7 years $(S D \pm 10.7)$. Mean duration of diabetes was 10.7 yrs. (SD \pm 7.7 ). A majority of patients were Urdu speaking (47.3\%) whereas others included Sindhi, Punjabi, Balochi, Pathan and others. Majority of the participants were educated, with only 16 (6.1\%) having no formal education. Most of the participants (89\%) were married. Table 1 shows demographic and clinical characteristics of the study participants.

Table 2 shows proportion of comorbid conditions among the participants. A higher percentage of patients had dyslipidemia $(76.1 \%)$ and hypertension $(72 \%)$. Among those who were obese $(\mathrm{n}=168)$, a higher percentage $(77 \%)$ reported a coexistence of hypertension with diabetes $(\mathrm{p}=0.01) .10 .8 \%$ of the men also reported to have erectile dysfunction.

\subsection{Adherence to Lifestyle Advice}

Adherence rate to lifestyle advice among participants is shown in Figure 1. Around 9.5\% of the participants were non-adherent to blood glucose monitoring and $25 \%$ were not fully-adherent to dietary advice. Almost $61.7 \%$ were non adherent to physical activity guidelines where most participants (93.2\%) reported to have awareness about the benefits of physical activity. About $43.4 \%$ of the participants used tobacco despite having knowledge about its health effects and $43.9 \%$ were non-adherent to foot care advice. None of the participants reported non-adherence to medications. About $57.2 \%$ of the participants were on oral hypoglycemic agents, $6.4 \%$ were on insulin and $36.4 \%$ were on a combination of oral anti-diabetic agents and insulin. Around $2.2 \%$ of the participants reported to consume alcohol either regularly or occasionally, $3.8 \%$ were ex-users whereas a majority of participants (93.9\%) reported to have never used alcohol.

Various forms of tobacco were found to be used by the participants. About $5.7 \%$ of the participants reported smoking currently, $9.5 \%$ were ex-smoker, $2.7 \%$ participants reported to smoke occasionally whereas most participants (82.2\%) reported to have never smoked. Median number of cigarette packs consumed by the current smokers was 182.5 whereas for ex-smokers it was 365. Only 2 of the participants reported to have consumed sheesha, 3 reported using naswaar and 19 reported using pan currently. Among the types of exercises reported by the participants, most reported mild walking (58.2\%) followed by brisk walk (26.7\%). a very few participants reported using Gym, stretching exercises and yoga. 


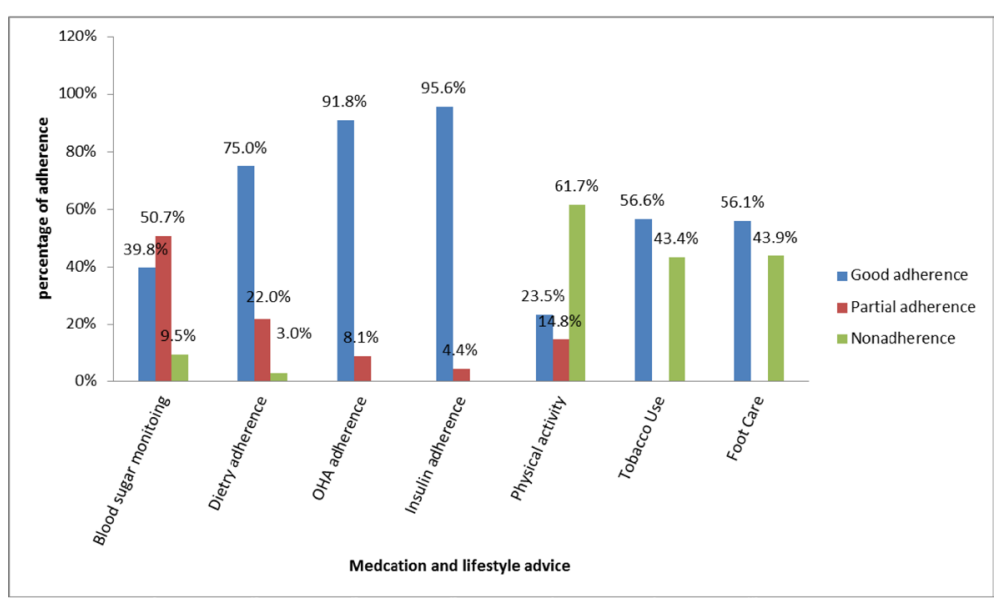

Figure 1. Distribution of patients according to self-reported adherence to lifestyle advice and treatment.

Table 1. Demographic and clinical characteristics of the study participants.

\begin{tabular}{|c|c|c|}
\hline Variables & & n (\%) \\
\hline \multirow[t]{2}{*}{ Duration of diabetes } & $\leq 7 \mathrm{yr}$ & 100 (37.9\%) \\
\hline & $>7 \mathrm{yr}$ & $164(62.1 \%)$ \\
\hline \multirow[t]{4}{*}{ Follow-up duration } & $<1 \mathrm{yr}$ & $58(22 \%)$ \\
\hline & $1-3 y r$ & $82(31.1 \%)$ \\
\hline & $4-6 \mathrm{yr}$ & 47 (17.8\%) \\
\hline & $>6 \mathrm{yr}$ & $77(29.2 \%)$ \\
\hline \multirow[t]{2}{*}{ Family history positive for diabetes } & Yes & $203(76.9 \%)$ \\
\hline & No & $61(23.1 \%)$ \\
\hline \multicolumn{3}{|l|}{ Waist circumference (males) } \\
\hline & Normal $(<90 \mathrm{~cm})$ & $9(6.9 \%)$ \\
\hline & Central obesity $(\geq 90 \mathrm{~cm})$ & $121(93.1 \%)$ \\
\hline \multicolumn{3}{|l|}{ Waist circumference (females) } \\
\hline & Normal $(<80 \mathrm{~cm})$ & $2(1.5 \%)$ \\
\hline & Central obesity ( $\geq 80$ ) & $132(98.5 \%)$ \\
\hline \multirow[t]{5}{*}{ BMI, mean (SD) } & & $29.0(5.2)$ \\
\hline & Underweight (<18.5) & $3(1.1 \%)$ \\
\hline & Acceptable (18.5 - 22.9) & $25(9.5 \%)$ \\
\hline & Overweight (23 - 24.9) & $29(11 \%)$ \\
\hline & Obese $(\geq 25)$ & $207(78.4 \%)$ \\
\hline \multirow[t]{3}{*}{ FBG, median (IQR) } & & $125(48)$ \\
\hline & $\leq 110$ (target) & $79(29.9 \%)$ \\
\hline & $>110$ (high) & $161(61 \%)$ \\
\hline \multirow[t]{3}{*}{ Triglycerides, Median (IQR) } & & $133.5(68)$ \\
\hline & $<150$ (target) & $143(54.2 \%)$ \\
\hline & $\geq 150$ (high) & $89(33.7 \%)$ \\
\hline \multirow[t]{5}{*}{ HBA1C, Mean (SD) } & & $7.3(1.5)$ \\
\hline & $\leq 6.9$ (controlled $)$ & $125(47.3 \%)$ \\
\hline & $7-8$ & $72(27.3 \%)$ \\
\hline & $8.1-9$ & $28(10.6 \%)$ \\
\hline & $\geq 9.1$ & $35(13.3 \%)$ \\
\hline \multirow[t]{3}{*}{ LDL, Mean (SD) } & & $79.7(28.9)$ \\
\hline & $<100$ (target) & $200(75.8 \%)$ \\
\hline & $\geq 100$ (high) & $49(18.6 \%)$ \\
\hline \multirow[t]{3}{*}{ HDL (males) Mean (SD) } & & $40.99(10.7)$ \\
\hline & $\geq 40$ (target) & $62(56.9 \%)$ \\
\hline & $<40$ & $47(43.1 \%)$ \\
\hline \multirow[t]{3}{*}{ HDL (females) Mean (SD) } & & $46.59(13.1)$ \\
\hline & $\geq 50$ (target) & $40(38.8 \%)$ \\
\hline & $<50$ & $63(61.2 \%)$ \\
\hline
\end{tabular}


Table 2. Comorbid conditions of the study participants.

\begin{tabular}{cc}
\hline Conditions & $\mathbf{n}(\mathbf{\%})$ \\
\hline Hypertension & $190(72 \%)$ \\
Ischemic Heart disease & $49(18.6 \%)$ \\
Dyslipidemia & $201(76.1 \%)$ \\
Obesity & $168(63.6 \%)$ \\
Retinopathy & $41(15.5 \%)$ \\
Nephropathy & $35(13.3 \%)$ \\
Neuropathy & $89(33.7 \%)$ \\
Diabetic foot & $6(2.3 \%)$ \\
Depression & $48(18.2 \%)$ \\
\hline
\end{tabular}

\subsection{Correlation of Different Factors with Adherence to Lifestyle Advice}

A significantly higher number of males reported to use tobacco (26.2\% among males vs. 6\% among females, p < $0.001)$. Also, a higher number of men reported good adherence to physical activity $(75.8 \%$ in men vs. $24.2 \%$ in women $\mathrm{p}<0.001)$. None of the women reported to use alcohol whereas $4.6 \%$ of men reported current alcohol use $(\mathrm{p}<0.001)$. No differences were observed in the categories of medication and dietary adherence across genders

\section{Education}

Most of the participants were educated in this group of participants. Around $46.6 \%$ of the participants had above high school education and only 6.1\% reported to have no formal education. Good adherence to physical activity was found to be highest in participants with more than high school education (33.3\% in high school education vs. 14.4 in less than or equal to high school education and $18.8 \%$ with no formal education $\mathrm{p}=0.01$ ). No significant differences were seen in self-reported dietary or medication compliance across the categories of education.

\section{Length of Diabetes}

A higher proportion of participants (62.1\%) had diabetes for more than seven years. Participants who had diabetes for more than seven years were more compliant to oral hypoglycemic agents as compared to those who had diabetes for less than or equal to 7 years $(63.1 \%$ vs. $36.9 \%$, p-value $=0.08)$

\section{Occupation}

A higher percentage of participants reporting tobacco use were business men (33.3\%), followed by salaried individuals $(26.2 \%)$, only $16.7 \%$ were homemakers $(\mathrm{p}=0.001)$. Of those who reported good adherence to physical activity (> 150 minutes/week) most were salaried individuals (33.9\%) followed by business men (32.3\%). Amongst those who reported partial adherence most $(53.8 \%)$ were homemakers $(\mathrm{p} \leq 0.001)$. Of those who reported alcohol consumption $(\mathrm{n}=16)$, 6 were salaried individuals whereas 9 were businessmen.

\section{Ethnic Background}

There were no differences in adherence based on ethnic background in this population.

\section{Glycemic Control}

Of the total 264 participants, 47.3\% had good glycemic control (HbA1c < 7\%). Table 3 shows the proportion of patients with good and suboptimal glycemic control according to patient characteristics and adherence to lifestyle advice. Diabetes was likely to be better controlled among those with lesser duration with diabetes, followup duration between 1 and 3 years and triglyceride level $<150$. Suboptimal glycemic control was more common among patients with ischemic heart disease (68.1\%), neuropathy (64.8\%), on insulin alone (62.5\%) and on combination of Insulin and OHA (69.8\%). 
Table 3. Proportion of patients with good and poor glycemic control according to demographic, clinical characteristics and adherence behaviors.

\begin{tabular}{|c|c|c|c|}
\hline Variables & $\begin{array}{c}\text { Good Glycemic Control } \\
\text { (HbA1c < 7\%) } \\
\text { n (\%) }\end{array}$ & $\begin{array}{c}\text { Suboptimal Control } \\
\text { (HbA1c } \geq 7 \%) \\
\text { n (\%) }\end{array}$ & P-value \\
\hline \multicolumn{4}{|l|}{ Age } \\
\hline$<50$ year & $34(45.3 \%)$ & $41(54.7 \%)$ & \multirow[t]{2}{*}{0.57} \\
\hline$\geq 50$ year & $91(49.2 \%)$ & $94(50.8 \%)$ & \\
\hline \multicolumn{4}{|l|}{ Gender } \\
\hline Male & $61(47.3 \%)$ & $68(52.7 \%)$ & \multirow{2}{*}{0.80} \\
\hline Female & 64 (48.9\%) & $67(51.1 \%)$ & \\
\hline \multicolumn{4}{|c|}{ Duration of Diabetes } \\
\hline$\leq 7$ & 55 (56.1\%) & $43(43.9 \%)$ & \multirow[t]{2}{*}{0.04} \\
\hline$>7$ & $70(43.2 \%)$ & $92(56.8 \%)$ & \\
\hline \multicolumn{4}{|c|}{ Follow-Up Duration } \\
\hline$<1 \mathrm{yr}$ & $21(37.5 \%)$ & 35 (62.5\%) & \multirow{4}{*}{0.02} \\
\hline $1-3 \mathrm{yr}$ & $49(61.3 \%)$ & $31(38.8 \%)$ & \\
\hline $4-6 \mathrm{yr}$ & $18(38.3 \%)$ & $29(61.7 \%)$ & \\
\hline$>6 \mathrm{yr}$ & 37 (48.1\%) & $40(51.9 \%)$ & \\
\hline \multicolumn{4}{|c|}{ Family History of Diabetes Mellitus } \\
\hline Yes & 95 (47.5\%) & $105(52.5 \%)$ & \multirow[t]{2}{*}{0.73} \\
\hline No & $30(50 \%)$ & $30(50 \%)$ & \\
\hline \multicolumn{4}{|l|}{ Central Obesity } \\
\hline Normal & $6(54.5 \%)$ & $5(45.5 \%)$ & \multirow[t]{2}{*}{0.66} \\
\hline Obesity & $119(47.8 \%)$ & $130(52.2 \%)$ & \\
\hline \multicolumn{4}{|c|}{ Body Mass Index (kg/m²) } \\
\hline Underweight & $1(33.3 \%)$ & $2(66.7 \%)$ & \multirow{4}{*}{0.46} \\
\hline Acceptable & $15(62.5 \%)$ & $9(37.5 \%)$ & \\
\hline Overweight & $14(50 \%)$ & $14(50 \%)$ & \\
\hline Obese & 95 (46.3\%) & $110(53.7 \%)$ & \\
\hline \multicolumn{4}{|l|}{ Hypertension } \\
\hline Yes & 87 (46.5\%) & $100(53.5 \%)$ & \multirow[t]{2}{*}{0.42} \\
\hline No & 38 (52.1\%) & 35 (47.9\%) & \\
\hline \multicolumn{4}{|l|}{ Hypertension } \\
\hline Yes & 87 (46.5\%) & $100(53.5 \%)$ & \multirow[t]{2}{*}{0.42} \\
\hline No & 38 (52.1\%) & 35 (47.9\%) & \\
\hline \multicolumn{4}{|c|}{ Ischemic Heart Disease } \\
\hline Yes & 15 (31.9\%) & 32 (68.1\%) & \multirow[t]{2}{*}{0.01} \\
\hline No & $110(51.6 \%)$ & $103(48.4 \%)$ & \\
\hline \multicolumn{4}{|l|}{ Dyslipidemia } \\
\hline Yes & $96(48.2 \%)$ & $103(51.8 \%)$ & 0.99 \\
\hline No & $28(47.5 \%)$ & 31 (52.5\%) & \\
\hline Obesity & & & \\
\hline Yes & 78 (46.7\%) & 89 (53.3\%) & 0.55 \\
\hline No & 47 (50.5\%) & 46 (49.5\%) & \\
\hline Retinopathy & & & \\
\hline Yes & $16(39 \%)$ & $25(61 \%)$ & (1) \\
\hline No & 103 (49.5\%) & $105(50.5 \%)$ & 0.42 \\
\hline Don’t Know & $6(54.5 \%)$ & $5(45.5 \%)$ & \\
\hline Nephropathy & & & \\
\hline Yes & $18(52.9 \%)$ & $16(47.1 \%)$ & 047 \\
\hline No & $106(47.1 \%)$ & 119 (52.9\%) & 0.47 \\
\hline Don’t Know & $1(100 \%)$ & 0 & \\
\hline Neuropathy & & & \\
\hline Yes & 31 (35.2\%) & 57 (64.8\%) & 0.003 \\
\hline No & 94 (54.7\%) & $78(45.3 \%)$ & \\
\hline
\end{tabular}




\begin{tabular}{|c|c|c|c|}
\hline \multicolumn{3}{|l|}{ Triglyceride } & \multirow{3}{*}{0.05} \\
\hline$<150$ & $75(52.8 \%)$ & $67(47.2 \%)$ & \\
\hline$\geq 150$ (high) & $35(39.8 \%)$ & $53(60.2 \%)$ & \\
\hline \multicolumn{3}{|l|}{ LDL } & \multirow{3}{*}{0.64} \\
\hline$<100$ (target) & $98(49.5 \%)$ & $100(50.5 \%)$ & \\
\hline$\geq 100$ (high) & $22(45.8 \%)$ & $26(54.2 \%)$ & \\
\hline \multicolumn{3}{|l|}{ Type of Treatment } & \multirow{4}{*}{$<0.001$} \\
\hline OHA Alone & $90(60.8 \%)$ & $58(39.2 \%)$ & \\
\hline Insulin Alone & $6(37.5 \%)$ & $10(62.5 \%)$ & \\
\hline OHA plus Insulin & $29(30.2 \%)$ & $67(69.8 \%)$ & \\
\hline \multicolumn{3}{|l|}{ Blood Glucose Monitoring } & \multirow{4}{*}{0.001} \\
\hline Good Adherence (>3 times/week) & $36(35 \%)$ & 67 (65\%) & \\
\hline Partial Adherence (1 - 3 times/week) & $78(58.6 \%)$ & $55(41.4 \%)$ & \\
\hline Non-Adherence (never) & $11(45.8 \%)$ & $13(54.2 \%)$ & \\
\hline \multicolumn{3}{|l|}{ Physical Activity } & \multirow{4}{*}{0.168} \\
\hline Good Adherence (regular physical activity $>150$ min/week) & $31(50.8 \%)$ & $30(49.2 \%)$ & \\
\hline Partial Adherence (regular 150 - 90 minutes/week) & $23(60.5 \%)$ & $15(39.5 \%)$ & \\
\hline Non-Adherence (sometimes <90 mints/week to none) & $71(44.1 \%)$ & $90(55.9 \%)$ & \\
\hline \multicolumn{3}{|l|}{ Self-Reported Dietary Compliance } & \multirow{4}{*}{0.68} \\
\hline Good Adherence & $93(47.2 \%)$ & $104(52.8 \%)$ & \\
\hline Partial Adherence & $27(49.1 \%)$ & $28(50.9 \%)$ & \\
\hline Non-Adherent & $5(62.5 \%)$ & $3(37.5 \%)$ & \\
\hline \multicolumn{3}{|l|}{ Medication Adherence (OHA) } & \multirow{4}{*}{0.22} \\
\hline Good Adherence (90\% - 100\%) & $111(50 \%)$ & $111(50 \%)$ & \\
\hline Partial Adherence (50\% - 89\%) & $8(36.4 \%)$ & $14(63.6 \%)$ & \\
\hline Non-Adherence $(<50 \%)$ & 0 & 0 & \\
\hline \multicolumn{3}{|l|}{ Medication Adherence (Insulin) } & \multirow{4}{*}{1.00} \\
\hline Good Adherence (90\% - 100\%) & $35(31.8 \%)$ & $75(68.2 \%)$ & \\
\hline Partial Adherence (50\% - 89\%) & $1(25 \%)$ & $3(75 \%)$ & \\
\hline Non-Adherence $(<50 \%)$ & 0 & 0 & \\
\hline
\end{tabular}

No significant differences were observed in the categories of tobacco use, alcohol use, foot care, education, occupation, marital status and presence of comorbid conditions such as erectile dysfunction, depression and diabetic foot.

\section{Discussion}

Our study reported lower non-adherence for self-monitoring of blood glucose (9.5\%) and lower percentage of participants who were not fully adherent to dietary advice (25\%) as compared to studies from other developing and developed countries [14]-[19]. Non adherence to physical activity was reported to be $61.7 \%$ in our study which was comparable to a study from Jordan (68\%) and higher than the ones reported from other settings [14] [15] [17] [19]. Our participants reported higher non-adherence rates (43.4\%) to tobacco advice as compared to other settings [14] [17]-[19]. Non-adherence to foot care advice (43.9\%) was almost similar to a study reported from Bangladesh [14]. Surprisingly, none of the patients from our study reported non-adherence to medications.

In our study, a combination of several factors including lesser duration with diabetes, follow up duration between 1 and 3 years and triglyceride level $<150$ was associated with good glycemic control (HbA1c $<7 \%$ ). Furthermore patients with suboptimal glycemic control were found to have strong association with ischemic heart disease (68.1\%), neuropathy (64.8\%), on insulin alone (62.5\%) and on combination of insulin and OHA (69.8\%). These results also showed that significant no of diabetic patients had comorbid conditions like obesity (78.4\%), dyslipidemia (76.1\%) and hypertension (72\%)

The results from previous studies have indicated poor glycemic control among those with increased duration of diabetes, lower level of education, higher BMI, hypercholesterolemia and elevated triglyceride levels. However, in our study glycemic control did not show any correlation with level of education or BMI. Physical activity was directly proportional to level of education but physical activity did not show any association with good glycemic control ( $\mathrm{p}$ value 0.168 ). This lack of association can probably be explained by the fact that in our study 
population $61.7 \%$ of the patients were non-adherent to the physical regimen that they were advised to follow.

This study was the first study conducted in Pakistan to determine adherence to lifestyle factors and their association with glycemic control. However, this study is cross sectional, where causal relationship between independent and dependent variables cannot be established, so a longitudinal study is needed to assess the relationship between those variables over time. This study was conducted in a specialized diabetic clinic, so the results might be different if compared with public sector hospitals or in the general population. These patients mostly undergo a detailed diabetes education program. Moreover, the study is self-reporting in nature and might involve reporting bias, using a more objective approach would be helpful.

\section{Conflict of Interests}

The all authors declared that they have no conflict of interests.

\section{Ethical Standards}

This research has been conducted on the humans after institutions' ethical review committee approval. Informed consent was obtained from all individual participants included in the study. This study was not funded.

\section{Authors Contribution}

SM led the conception and design, acquisition of data, review of literature, and drafted the manuscript.

RK helps in design, literature search and drafting of manuscript.

SN involved in acquisition of data and review of literature.

MM reviewed the manuscript and involved in statistical analysis and results formulation.

JA supervised and provided expertise for the overall design of study and critically reviewed the manuscript.

\section{References}

[1] Rise, M.B., Pellerud, A., Rygg, L.Ø. and Steinsbekk, A. (2013) Making and Maintaining Lifestyle Changes after Participating in Group Based Type 2 Diabetes Self-Management Educations: A Qualitative Study. PLoS One, 8, e64009. http://dx.doi.org/10.1371/journal.pone.0064009

[2] http://www.idf.org/sites/default/files/EN 6E Atlas Full 0.pdf

[3] Ganiyu, A.B., Mabuza, L.H., Malete, N.H., Govender, I. and Ogunbanjo, G.A. (2013) Non-Adherence to Diet and Exercise Recommendations amongst Patients with Type 2 Diabetes Mellitus Attending Extension II Clinic in Botswana. African Journal of Primary Health Care \& Family Medicine, 5, Art. No. 457.

[4] WHO. Adherence to Long-Term Therapies_Evidence for Action 2003. http://www.who.int/chp/knowledge/publications/adherence_full_report.pdf

[5] Saleh, F., Mumu, S.J., Ara, F., Hafez, M.A. and Ali, L. (2014) Non-Adherence to Self-Care Practices \& Medication and Health Related Quality of Life among Patients with Type 2 Diabetes: A Cross-Sectional Study. BMC Public Health, 14, 431. http://dx.doi.org/10.1186/1471-2458-14-431

[6] Khattab, M., Khader, Y.S., Al-khawaldeh, A. and Ajlouni, K. (2010) Factors Associated with Poor Glycemic Control among Patients with Type 2 Diabetes. Journal of Diabetes and Its Complications, 24, 84-89. http://dx.doi.org/10.1016/j.jdiacomp.2008.12.008

[7] Habib, S.S. and Aslam, M. (2003) Risk Factors, Knowledge and Health Status in Diabetic Patients. Saudi Medical Journal, 24, 1219-1224.

[8] Al-Sultan, F.A. and Al-Zanki, N. (2005) Clinical Epidemiology of Type 2 Diabetes Mellitus in Kuwait. Kuwait Medical Journal, 37, 98-104.

[9] Sebo, P., Albetel, G., Stalder, H. and Bovier, P.A. (2006) Importance of Lifestyles Counselling by Primary Care Physicians for Diabetic Patients. Swiss Med Wkly, 136, 566-573.

[10] Neel, J.V. (1999) Diabetes Mellitus: A “Thrifty“ Genotype Rendered Detrimental by "Progress”? Bulletin of the World Health Organisation, 77, 694-703.

[11] Tuomilehto, J. and Wolf, E. (1987) Primary Prevention of Diabetes Mellitus. Diabetes Care, 10, 238-248. http://dx.doi.org/10.2337/diacare.10.2.238

[12] Tuomilehto, J., Tuomilehto-Wolf, E., Zimmet, P., Alberti, K. and Knowler, W. (1997) Primary Prevention of Diabetes Mellitus. In: Alberti, K., Zimmet, P., DeFronzo, R., Keen, H., Eds., International Textbook of Diabetes Mellitus, John Wiley, Chichester, 1799-1827. 
[13] Hordern, M.D., Dunstan, D.W., Prins, J.S., Baker, M.A., Singh, M.A. and Coombes, J.S. (2012) Exercise Prescription for Patients with Type 2 Diabetes and Pre-Diabetes: A Position Statement from Exercise and Sport Science Australia. Journal of Science and Medicine in Sport, 15, 25-31. http://dx.doi.org/10.1016/j.jsams.2011.04.005

[14] Gray-Sevilla, M.E., Nava, L.E., Malacara, J.M., Huerta, R., De-Leon, J.D., Mena, A., et al. (1995) Adherence to Treatment and Social Support in Patients with Non-Insulin Dependent Diabetes Mellitus. Journal of Diabetes and Its Complications, 9, 81-86. http://dx.doi.org/10.1016/1056-8727(94)00021-F

[15] Vincze, G., Barner, J.C. and Loperz, D. (2004) Factors Associated with Adherence to Self-Monitoring of Blood Glucose among Persons with Diabetes. The Diabetes Educator, 30, 112-125. http://dx.doi.org/10.1177/014572170403000119

[16] Hanko, B., Kazmer, M., Kumli, P., Hragyel, Z., Samu, A., Vincze, Z., et al. (2007) Self-Reported Medication and Lifestlye Adherence in Hungarian Patients with Type 2 Diabetes. Pharmacy World \& Science, 29, 58-66. http://dx.doi.org/10.1007/s11096-006-9070-2

[17] Wild, S., Roglic, G., Green, A., Sicree, R. and King, H. (2004) Global Prevalence of Diabetes: Estimates for the Year 2000 and Projections for 2030. Diabetes Care, 27, 1047-1053. http://dx.doi.org/10.2337/diacare.27.5.1047

[18] Raum, E., Kramen, H.U., Ruter, G., Rotherbacher, D., Rosemann, T., Szecsenyi, J., et al. (2012) Medication Non-Adherence and Poor Glycemic Control in Patients with Type 2 Diabetes Mellitus. Diabetes Research and Clinical Practice, 97, 377-384. http://dx.doi.org/10.1016/j.diabres.2012.05.026

[19] Mumu, S.J., Saleh, F., Ara, F., Afnan, F. and Ali, L. (2014) Non-Adherence to Life Style Modification and Its Factors among Type 2 Diabetic Patients. Indian Journal of Public Health, 58, 40-44. http://dx.doi.org/10.4103/0019-557X.128165 